\title{
Comentario al texto de Francisco Saffie "La racionalidad de los impuestos. Una tarea de reconciliación"
}

\author{
On Francisco Saffie's "The Rationality of Taxes. A \\ Task of Reconciliation"
}

Eleonora Lozano Rodríguez

Recepción: 15/08/19

Evaluación: 18/08/19

Aceptación final: 30/09/19

\begin{abstract}
Resumen: Este texto es una reacción a la argumentación propuesta por Francisco Saffie por la cual el "reconocimiento recíproco" da lugar al comportamiento solidario y ético de los hombres en el cumplimiento de sus obligaciones tributarias. Lo anterior por cuanto, para el autor, existe una fuerte relación entre la tributación y el derecho a la propiedad privada, lo que llevaría a construir el derecho tributario sobre principios. El comentario al texto diserta, en primer lugar, sobre los conceptos de "ética" y "moralidad" e intenta comprender cómo el "reconocimiento recíproco" incentiva en los hombres estas cualidades. También ahonda en la dificultad de entender qué son los "principios jurídicos" para analizar la construcción del derecho tributario sobre los mismos.
\end{abstract}

Palabras clave: Moral tributaria, Ética tributaria, Cumplimiento tributario, Principio jurídico

\footnotetext{
Profesora Asociada de la Facultad de Derecho de la Universidad de los Andes, Bogotá, Colombia. Directora del Doctorado en Derecho y de la Maestría en Tributación de la misma universidad. Abogada, economista y magíster en economía de la Universidad de los Andes. Doctora en Derecho de la Universidad de Salamanca, España. Correo electrónico: elozano@uniandes.edu.co. Página web: www.eleonoralozano.com
} 


\begin{abstract}
This text is a reaction to the argumentation proposed by Francisco Saffie whereby "reciprocal recognition" gives rise to the solidary and ethical behavior of men in the fulfillment of their tax obligations. This is because, for the author, there is a strong relationship between taxation and the right to private property, which would lead to the construction of the tax law on principles. The commentary to the text speaks, first of all, about the concepts of "ethics" and "morality" and tries to understand how "reciprocal recognition" encourages these qualities in men. It also delves into the difficulty of understanding what are the "legal principles" to analyze the construction of tax law on them.
\end{abstract}

Key words: Morality of Taxes, Ethics of Taxes, Fiscal Fulfillment, Legal Principle

\title{
1. La propuesta argumentativa del autor
}

Francisco argumenta que los impuestos no se justifican solo en términos instrumentales, es decir no hallan exclusivamente su razón de ser en el financiamiento del gasto público, la redistribución y la regulación de ciertas actividades que generan externalidades negativas. Para él la tributación y el derecho tributario pueden tener un bien intrínseco o interno, y este consiste básicamente en el "reconocimiento recíproco". Este último surge además de la muy fuerte relación que existe entre tributación y propiedad privada, para demostrar que la obligación de pagar impuestos se justifica mientras que esta última exista.

Para comprender la noción de "bien interno" y distinguirla de las "instituciones" se apoya en MacIntyre y en Honneth para sostener que nuestro desarrollo como seres humanos está condicionado por las interacciones sociales, y más concretamente, en el reconocimiento recíproco.

Plantea el autor una idea maravillosa que cito

Los sistemas tributarios son parte de los arreglos conforme a los que se distribuyen bienes entre los miembros de una comunidad política y constituyen un aspecto importante del vivir juntos, puesto que aseguran las condiciones materiales para hacerlo posible. En 
Comentario al texto de Francisco Saffie "La racionalidad de los impuestos...

este sentido, esta práctica es parte de una evolución histórica, dentro de la cual el reconocimiento en las esferas del derecho y del Estado han hecho posible el desarrollo libre de los sujetos permitiendo su auto-realización siendo parte de las instituciones que caracterizan al Estado moderno. La práctica de los impuestos es parte de una vida ética y es esencial para la solidaridad (resaltad fuera de texto) (Saffie, 2020, sección 5.1).

Para sustentar lo anterior, explora la relación entre propiedad privada y tributación para darle sustento a la "reciprocidad". Concluye, siguiendo a Murphy y Nagel, que la definición de propiedad privada depende de la tributación y que la tributación, entonces, no se justificaría únicamente sobre bases instrumentales. Existirían, por lo tanto, nuevos fundamentos. Dice Francisco que la tributación es la "expresión de la solidaridad", y de ahí que surja una consecuencia importante de la obligación de pagar impuestos, donde “(e)la no dependerá más de la voluntad del individuo, sino de la existencia objetiva del derecho a la propiedad privada" (Saffie, 2020, sección 5.2).

Para el autor, retomando a Hegel, el derecho a la propiedad privada

se trata de un derecho que nos garantiza el espacio para la expresión objetiva en el mundo de nuestra voluntad subjetiva. Esta definición del derecho a la propiedad privada posee un límite intrínseco: el reconocimiento de la propiedad privada de otros. $\mathrm{O}$ lo que es lo mismo, asegurar espacios de libertad y desarrollo de la personalidad a todos. Un sistema de propiedad privada y un sistema tributario son las dos caras de una misma moneda, porque los impuestos representan la forma de asegurar libertad para todos; la posibilidad del desarrollo ético de sujetos libres (subrayado fuera de texto) (Saffie, 2020, sección 5.2).

Concluye el texto diciendo:

Todo individuo al que se le reconozca un derecho de propiedad privada tendrá el deber de pagar impuestos como sujeto que forma parte de un Estado. El deber legal de pagar impuestos no puede justificarse en términos meramente instrumentales; sino que 
formará parte de la propiedad privada. Esta segunda conclusión podría dar un mejor fundamento a la propuesta de Freedman (...) sobre reconstruir el derecho tributario como legislación basada en principios (Saffie, 2020, sección 5.2).

De lo anterior, concluyo que el iter argumentativo de Francisco tiene las siguientes etapas:

i. La tributación y el derecho tributario tiene un bien intrínseco que es el "reconocimiento recíproco".

ii. Este "reconocimiento recíproco" da lugar al comportamiento solidario y ético de los hombres.

iii. El sustento de ese "reconocimiento recíprico" es la fuerte relación que existe entre la "tributación" y el "derecho a la propiedad privada".

iv. El "derecho a la propiedad privada" permite la "libertad" y el "libre desarrollo de la personalidad", así como el desarrollo "ético" de las personas.

v. Todo lo anterior, da mejor sustento a la idea de Freedman de construir el derecho tributario sobre principios.

\section{Reacción a partir de mis líneas de investigación}

Parto de dos (2) afirmaciones contundentes. Primero, no me queda claro qué es la ética para el autor y porqué el "reconocimiento recíproco" da lugar al comportamiento "ético" de los hombres; y segundo, no comprendo porqué la relación entre "tributación y derecho de propiedad" sustenta la posible construcción del derecho tributario sobre principios y no sobre derecho positivo.

\subsection{El problema de la "moralidad" tributaria}

A partir de planteamientos filosóficos, en Lozano \& Tamayo (2014) nos referimos a la "ética" como la ciencia o disciplina que lleva a cabo el análisis del lenguaje moral y que ha elaborado diferentes teorías y maneras de justi- 
Comentario al texto de Francisco Saffie "La racionalidad de los impuestos...

ficar y de revisar críticamente las pretenciones de validez de los enunciados morales. Así, la ética es una "ciencia" que pertenece al campo de la filosofía, mientras que lo "moral" es, en general, el objeto de estudio de la misma (p.3). En ese capítulo citamos a Tipke para quien la "ética tributaria" se enfoca en estudiar la moralidad en materia tributaria desarrollada por los poderes públicos, por el ciudadano y por los demás actores de un sistema (2002, p.21). Así, Francisco tal vez se debería referir al desarrollo "moral" más que "ético" de los ciudadanos libres.

Pero superando las problemáticas conceptuales, en Lozano \& Tamayo (2014) indagamos si la "moral" influye o no en el nivel de cumplimiento tributario de los contribuyentes. Descubrimos que son varias las variables que influyen en el comportamiento de las personas en lo que respecta a sus responsabilidades tributarias, que podrían dividirse en dos grupos. En el primero, aquellas que responden al análisis económico del cumplimiento tributario donde, retomando a Alligman y Sandmo (1972), los contribuyentes deciden evadir impuestos de la misma manera como se aproximan a cualquier decisión riesgosa que toman en un juego de azar y son influenciados por las posibles sanciones penales como cualquier otro costo continguente. Así, una óptima evasión dependerá de la posibilidad de ser "atrapado" y penalizado por la autoridad tributaria, del tamaño de la sanción por evasión que se va a imponer y del grado de aversión al riesgo que tenga el individuo (p. 29 y 30 ).

En un segundo grupo demostramos cómo existen consideraciones morales que influyen en los comportamientos elusivos o evasivos de los contribuyentes y que estas se encuentran a su vez incididas por las características de la población contribuyente (según literatura internacional, los hombres evaden más que las mujeres y los contribuyentes casados presentan mayores niveles de incumplimiento (Lozano \& Tamayo, 2014, p. 37), el comportamiento de otros contribuyentes (la información que los individuos tienen respecto de la actuación evasiva o no de terceros contribuyentes influye en su decisión de cumplimiento tributario, (p. 36)), la justicia y la percepción del sistema tributario (leyes tributarias que son consideradas injustas por contribuyentes no son cumplidas, (p. 37)), el nivel de corrupción a la hora de ejecutar el gasto público (la moral del contribuyente será mayor y la evasión menor si los motivos de queja frente 
al gobierno sean menores, (p. 39)), y la rectitud de los ejecutivos y las políticas empresariales (las inclinaciones hacia la elusión tributaria de los ejecutivos que administran una firma desempeñan un papel significativo en la determinación del nivel de elusión que una determinada firma asume, (p. 41)) ${ }^{1}$. Así concluimos que las motivaciones morales desempeñan un papel importante en el cumplimiento tributario más allá de las simples consideraciones económicas del individuo.

Por lo anterior, no solo las razones de solidaridad y de "reconocimiento recíproco" que esboza Francisco llevan a los individuos a cumplir sus obligaciones tributarias ni permiten el "desarrollo ético de sujetos libres". Existen otras motivaciones.

\subsection{La construcción axiológica del derecho tributario}

Respaldo a Freedman en que la legislación tributaria debe soportarse en principios. Sin embargo, como lo reconocimos con Mendoza (Lozano y Mendoza, 2008), el problema consiste en la vaguedad en la definición del concepto de "principios jurídicos". Es así como relacionamos varias conceptualizaciones que los han entendido como valores superiores el ordenamiento jurídico; directrices; normas generales; normas de selección, aplicación o interpretación normativa; máxima de una disciplina que permite la sistematización del sistema jurídico; mandatos de optimización; entre otros.

Pese a lo anterior, y siguiendo a Alexy, resaltábamos su importancia para la hermenéutica tributaria dado el uso judicial frecuente de las técnicas de "ponderación" entre principios opuestos. Para este autor,

"los principios son 'mandatos de optimización. En tanto tales, son normas que ordenan que algo se realice en la mayor medida posible según las posibilidades fácticas y jurídicas... las posibilidades jurídicas de la realización de un principio están determinadas esencialmente, a más de... por los principios opuestos" (Alexy, 2004).

1 Para conocer a mayor profundidad el desarrollo de cada una de estas variables ver páginas 35 a 44 (Lozano y Tamayo, 2014). 
Comentario al texto de Francisco Saffie "La racionalidad de los impuestos...

Así presentábamos, para el caso colombiano, el uso por parte de Corte Constitucional de las pruebas de razonabilidad, el núcleo esencial de los derechos y la jerarquización de principios" (Lozano y Mendoza, p. 70).

En mis cursos de hermenéutica jurídica sigo a Guastini (2010) para quien resulta muy importante distinguir entre las normas que son principios y aquellas que son reglas, por cuanto los principios resultan esenciales para el adecuado funcionamiento del razonamiento jurídico, en especial en lo judicial. De esta manera los principios pueden ser usados por el juez constitucional para decidir acerca de la conformidad de una norma de ley con la Constitución, o por un juez ordinario para colmar alguna laguna en la ley (Guastini, 2010, p. 210-211).

También se refiere Guastini al "análisis lógico de ponderación” donde, siguiendo a Dworkin (1977), consiste en atribuir a uno de los dos principios en conflicto un "peso", un valor o una "importancia" ético-política" (Guastini, 2010, p. 211). Para esto se refiere a la "concreción", es decir el uso de los principios para elaborar reglas no expresas; así como a la "subsunción" o utilizar un concepto par resolver una colisión de principios (Guastini, 2010, p. 220-228).

Finalmente, para Guastini, "la ponderación de principios no es una operación interpretativa en sentido estricto: pertenece sobre todo al dominio de la construcción jurídica”, aunque reconoce que la interpretación está en el fondo (Guastini, 2010, p. 234).

Sin embargo, no queda claro cómo para Francisco si el "derecho a la propiedad privada" permite la "libertad" y el "libre desarrollo de la personalidad", y esto conlleva a un desarrollo "ético" de las personas, se dará un mejor sustento a la idea de construir el derecho tributario sobre principios. Veo, por lo tanto, como lo reconoció Guastini, una dificultad en entender cuáles normas son reglas o principios. Para este caso pareciera que los derechos a la propiedad, a la libertad y al libre desarrollo de la personalidad son normas y no principios. ¿Cuáles serán entonces los principios a los cuales Francisco se refiere? 


\section{Bibliografía}

Alexy, R. (2004). El concepto y la validez del derecho. Barcelona: Gedisa. Allinghman, M.F., y Sandmo, A. (1972). Income tax evasion: A theorical analysis. Journal of Public Economics, 1, 323-328.

Dworkin, R. (1977). Los derechos en serio. Cambridge: Harvard University Press.

Guastini, R. (2010). Nuevos estudios sobre la interpretación. Bogotá: Universidad Externado.

Lozano, E. y Tamayo, D. (2014). Ética y tributación. En E. Lozano (coord.), Estudios Interdisciplinarios de la Tributación (pp 1-77). Bogotá: Ediciones Uniandes.

Lozano, E. (2016). Parte teórica. Hacia un nuevo enfoque del análisis económico del derecho. En Lozano, E. (coord), Teoría y puesta en práctica del Análisis Económico del Derecho (pp. 1-64). Bogotá: Ediciones Uniandes.

Lozano, E., y Mendoza, C. (2008). Hermenéutica Tributaria. En E. Lozano (coord), Fundamentos de la Tributación (pp. 44-75). Bogotá: Universidad de los Andes y Temis.

Saffie, F. (2020). La racionalidad de los impuestos. Una tarea de reconciliación. Discusiones, 25(2).

Tipke, K. (2002). Moral tributaria del Estado y de los contribuyentes. Madrid: Marcial Pons. 